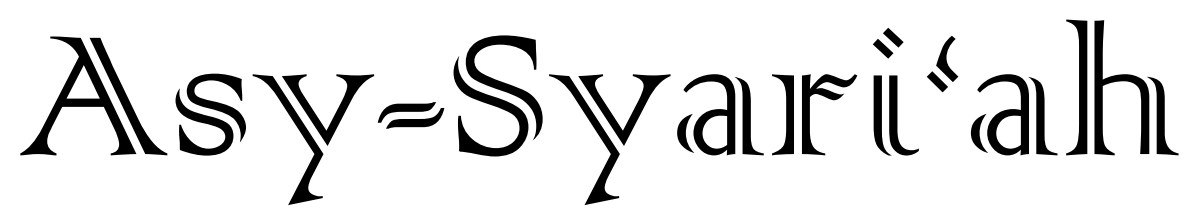

- $\quad$ The Role of Religious Court in Islamic Law Reform in Indonesia

$(125-134)$ Amran Suadi

- Rechtvinding tentang Waris Beda Agama di Pengadilan Agama ( $135-158)$ Kota Bandung Siah Khosyi'ah dan Aan Tsamrotul Fuadah

- Dualisme Kedudukan dan Tanggung Jawab Notaris dalam ( $159-170)$ Tatanan Sistem Hukum Nasional Isis Ikhwansyah dan Indra Prayitno

- Nilai-Nilai Keislaman dalam Konstitusi Kesultanan Ngayogyakarta Hadiningrat

Abdul Rohim Al Wafi

- Anotasi Putusan Dissenting Opinion dalam Putusan Kasasi Taufik Maulani

- Dampak Poligami Siri Terhadap Kehidupan Keluarga di Desa Cigugur Girang, Bandung Barat Ade Darmawijaya

- Azas-Azas dan Landasan Distribusi Pendapatan dalam Islam $(221-232)$ Rani Mulyani dan Iwan Setiawan

- Eksistensi Riba dalam Investasi Wakaf Uang di Luar Bank (233-244) Syari'ah

Khoir Affandi

- Hak Pendidikan bagi Penyandang Disabilitas dalam Perspektif Hukum Perdata dan Hak Asasi Manusia

Ikbar Maulana Malik

- Perspektif Hukum Islam dalam Penyelesaian Sengketa Melalui ( $257-280$ ) Mediasi di Badan Penyelesaian Sengketa Konsumen Kota Mataram Irma Istihara Zain 


\section{Asy-Syauri'ah}

Volume 21, Number 2, 2019

\section{EDITOR-IN-CHIEF}

Ine Fauzia

\section{EDITORIAL BOARD}

Sofyan al-Hakim, UIN Sunan Gunung Djati Bandung, Indonesia Deni Kamaludin Yusup, UIN Sunan Gunung Djati Bandung, Indonesia Meria Utama, Fakultas Hukum Univrsitas Sriwijaya, Indonesia Dewi Mayaningsih, UIN Sunan Gunung Djati Bandung, Indonesia Andrey Sujatmiko, Fakultas Hukum Universitas Trisakti, Jakarta, Indonesia Hetty Hassanah, Universitas Komputer Indonesia, Indonesia

\section{PEER-REVIEWERS}

Muhammad Irfan Helmy, IAIN Salatiga, Semarang, Indonesia Ahmad Ali Nurdin, UIN Sunan Gunung Djati Bandung Tajul Arifin, UIN Sunan Gunun Djati Bandung, Indonesia Mohamad Anton Athoillah, UIN Sunan Gunung Djati Bandung, Indonesia Mrs. Renny Supriyatni, Universitas Padjadjaran, Indonesia Ahmad Tholabi Karlie, UIN Syarif Hidayatullah Jakarta, Indonesia Ija Suntana, UIN Sunan Gunung Djati Bandung, Indonesia Zezen Zaenal Mutaqin, University of California, Los Angeles, United States Ahmad Fathonih, UIN Sunan Gunung Djati Bandung, Indonesia Rahman Syamsuddin, Universitas Islam Negeri Alauddin Makassar, Indonesia

\section{PROOFREADER/DESIGN COVER}

Nanang Sungkawa

\section{LAYOUT EDITOR}

Opik Rozikin

Asy-Syari' ah has been accredited based on the determination of Director General of Research and Development Strengthening, Ministry of Research, Technology and Higher Education of Republic of Indonesia, No. 14/E/KPT/2019 (valid until 2023). 


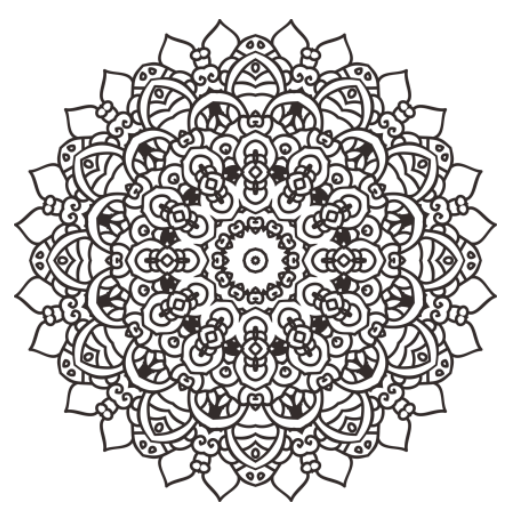

\title{
EKSISTENSI RIBA DALAM INVESTASI WAKAF UANG DI LUAR BANK SYARI'AH
}

\author{
Khoir Affandi \\ Pascasarjana UIN Sunan Gunung Djati Bandung \\ Email: filbarokah@gmail.com
}

\begin{abstract}
According to the legal facts, the management and development of waqf money is carried out in accordance with the principles of sharia and does not conflict with the regulations of the Indonesian law. But according to the facts on the ground there is still usury in the management and development of the endowments of the money. This can be seen by the obligatory Nazir to guarantee the endowments of money managed and developed outside the shari'ah bank into shari'ah insurance. Thus, waqf money can only increase, whereas in the management and development of waqf money, Nazir can not always gain profits, there are times when Nazir loses and when Nazir experiences profit then it is done for profit between Nazir, mauquf 'alaih and Islamic financial institutions' Ah, but in the case of Nazhir's loss, the loss will be borne entirely by Nazhir. if this concept is applied in the management and development of money waqf, then what is the difference between a sharia financial institution and another bank that is not a sharia that applies the usury principle?
\end{abstract}

Keyword: Indonesia, usury, waqf 
Abstrak: Menurut fakta hukum, pengelolaan dan pengembangan wakaf uang dilakukan sesuai dengan prinsip syari'ah dan tidak bertentangan peraturan perwakafan di Indonesia. Akan tetapi menurut faktanya di lapangan masih terdapat riba dalam pengelolaan dan pengembangan wakaf uang tersebut. Hal ini terlihat dengan diwajibkannya nazhir untuk menjaminkan wakaf uang yang dikelola dan dikembangkanya di luar bank syari'ah ke dalam asuransi syari'ah. Dengan demikian, wakaf uang hanya boleh bertambah, padahal dalam pengelolaan dan pengembangan wakaf uang, tidak selamanya nazhir dapat meraih keuntungan, ada kalanya nazhir mengalami kerugian dan pada saat nazhir mengalami keuntungan maka dilakukan bagi keuntungan antara nazhir, mauquf 'alaih dan lembaga keuangan syari'ah akan tetapi dalam kondisi nazhir mengalami kerugian maka kerugian tersebut akan ditanggung seluruhnya oleh nazhir. Apabila konsep ini yang diberlakukan dalam pengelolaan dan pengembangan wakaf uang, maka apa bedanya lembaga keuangan syari'ah dengan bank lainya yang bukan syari'ah yang menerapkan prinsip riba?

Kata Kunci: Indonesia, riba, wakaf 


\section{Pendahuluan}

Undang undang Wakaf menyatakan bahwa, investasi wakaf uang harus dilakukan sesuai dengan prinsip syari'ah. Aturan ini dapat kita temukan dalam Pasal 43 Ayat (1) Undang-Undang Nomor 41 Tahun 2004 Tentang Wakaf, "Pengelolaan dan pengembangan harta benda wakaf oleh Nazhir sebagaimana dimaksud dalam Pasal 42 dilaksanakan sesuai dengan prinsip syariah".

Akan tetapi, menurut fakta lapanganya, investasi wakaf uang yang dilakukan luar bank syari'ah tidak dilaksanakan sesuai dengan prinsip syari'ah karena masih terdapat unsur riba dalam pelaksanaanya, hal ini dapat kita lihat pada Pasal 43 Ayat (3) UndangUndang Nomor 41 Tahun 2004 Tentang Wakaf jo Pasal 48 Ayat (5) Peraturan Pemerintah Nomor 25 Tahun 2018 Tentang Pelaksanaan Undang-Undang 41 Tahun 2004 Tentang Wakaf, "Dalam hal pengelolaan dan pengembangan harta benda wakaf yang dimaksud pada ayat (1) diperlukan penjamin, maka digunakan lembaga penjamin syariah". "Pengelolaan dan pengembangan atas harta benda wakaf uang yang dilakukan dalam bentuk investasi di luar bank syariah harus diasuransikan pada asuransi syariah".

Berikut ini data wakaf uang dari tahun 2009 sampai tahun 2011:

\begin{tabular}{|c|c|c|}
\hline No & Bank & Jumlah \\
\hline 1 & BNI Syari'ah & Rp.40.313.000,- \\
\hline 2 & Mandiri Syari'ah & Rp.441.766.141,- \\
\hline 3 & Mu'amalat & Rp.7.000.000,- \\
\hline 4 & DKI Syari'ah & Rp.5.350.000,- \\
\hline 5 & Mega Syari'ah & Rp.9.108.000,- \\
\hline \multicolumn{2}{|c|}{ Total wakaf uang 2009} & Rp.503.537.141,- \\
\hline No & Bank & Jumlah \\
\hline 1 & BNI Syari'ah & Rp. $370.434 .000,-$ \\
\hline 2 & Mandiri Syari'ah & Rp. 927.806.732,- \\
\hline 3 & Mu'amalat & Rp.96.100.621,- \\
\hline 4 & DKI Syari'ah & Rp.185.154.300,- \\
\hline 5 & Mega Syari'ah & Rp.173.496.865,- \\
\hline \multicolumn{2}{|c|}{ Total wakaf uang 2010} & Rp. 1.752.992.968,- \\
\hline No & Bank & Jumlah \\
\hline 1 & BNI Syari'ah & Rp. 56.750.000 \\
\hline 2 & Mandiri Syari'ah & Rp. 831.838.757 \\
\hline 3 & Mu'amalat & Rp. 93.422.493 \\
\hline 4 & DKI Syari'ah & Rp. $25 \cdot 491.891$ \\
\hline 5 & Mega Syari'ah & Rp. 30.064 .725 \\
\hline & Total wakaf uang 2011 & Rp. 1.037 .567 .866 \\
\hline
\end{tabular}

Sumber: Laporan Keuangan BWI 2009-2011

${ }^{1}$ Abdullah Ubaid, Analisis Hasil dan Metode Fundraising Wakaf Uang Badan Wakaf Indonesia (BWI), Jurnal Bimas Islam, Vol. 7, Tahun 2014, ISSN: 1978-9009, (Jakarta: 2014), hal 611-619 
Pokok permasalahannya penulis melalui tulisan ini ingin mengatakan bahwa Badan Wakaf Indonesia telah menyadari bahwa dalam dunia investasi, kerugian dan keuntungan merupakan hal yang lazim terjadi. Apabila nazhir melakukan investasi wakaf uang dan mengalami kerugian, maka wakaf uang tersebut dapat hilang, sedangkan pada prinsipnya, wakaf uang tidak boleh hilang. Oleh karena itu, digunakanlah asuransi syari'ah untuk mencegah hilangnya wakaf uang pada saat terjadi kerugian. Pada saat dana asuransi syari'ah tidak dapat dikembalikan melalui keuntungan investasi wakaf uang tersebut, maka nazhir menurut aturan ini wajib bertanggung jawab mengembalikan seluruh kerugian tersebut.

Menurut penulis, konsep pelaksanaan wakaf uang yang seperti ini sama seperti pinjam meminjam untuk kegiatan investasi dengan menggunakan jasa rentenir, karena uang yang nazhir pinjam tidak boleh mengalami kerugian dan jika mengalami kerugian maka nazhir wajib mengembalikan pinjaman uang yang ditambahkan dengan bunga asuransi pinjaman tersebut.

Terminologi wakaf. Menurut peraturan perwakafan di Indonesia, Wakaf adalah perbuatan hukum wakif untuk memisahkan dan/atau menyerahkan sebagian harta benda miliknya untuk dimanfaatkan selamanya atau untuk jangka waktu tertentu sesuai dengan kepentinganya guna keperluan ibadah dan/atau kesejahteraan umum menurut syari'ah. Sedangkan pengertian wakaf menurut para ahli fiqih:

Hanafiyah

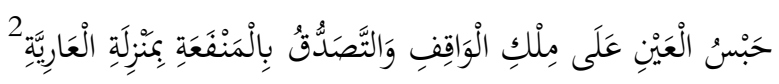

Wakaf merupakan kegiatan pemanfaatan harta benda wakaf dengan pola sewa menyewa dengan menetapkan kepemilikan harta benda wakaf tersebut pada wakif dan tugas agar harta benda wakaf tersebut tetap ada pada wakif.

Malikiyah

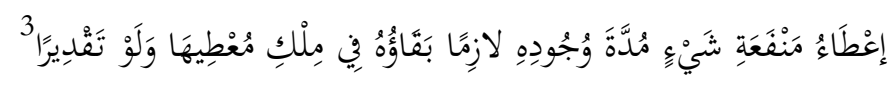

Wakaf merupakan kegiatan memanfaatkan harta benda wakaf selama harta benda wakaf tersebut ada dan dapat dimanfaatkan dengan mewajibkan agar harta benda wakaf tersebut tetap ada atau tidak hilang karena dimanfaatkan dan tugas tersebut dibebankan kepada wakif atau yang mewakilinya seperti nazhir.

Syafi'iyah

http://simbi.kemenag.go.id/pustaka/images/materibuku/Buku\%20Jurnal\%207.4.pdf diakses pada tanggal 1 Agustus 2019

${ }^{2}$ Amin bin Umar (Ibnu Abidin), Muhammad. raddu muhtar ala addarul mukhtar, Jilid 3 (t. Ihya atTurats.T.th). hlm. 357-358.

${ }^{3}$ Muhammad Ilyas. Sarah Min al-jalil 'ala Mukhtasorul alamat al kholil, Jilid 4 (t. Daar shadir. T.th.) hlm. 34 


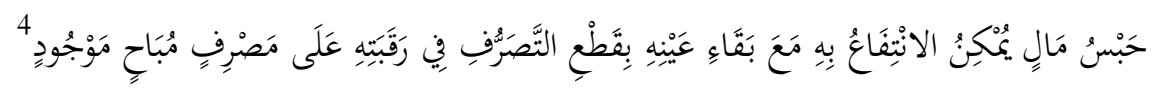

Wakaf merupakan kegiatan menjaga harta benda wakaf agar harta benda wakaf tetap ada dan memanfaatkan harta benda wakaf tersebut dengan memutuskan seluruh hak wakif dalam kepemilikan harta benda wakaf, kemudian, hasil pemanfaatan harta benda wakaf tersebut diberikan kepada mereka yang berhak menerima pemanfaatan harta benda wakaf tersebut.

Hanabilah

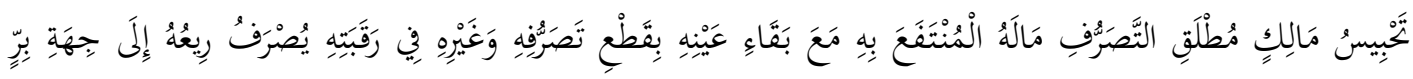

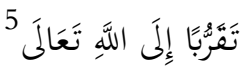

Wakaf merupakan kegiatan memutuskan hak wakif atau orang lain terkait wakaf tersebut dalam kepemilikan harta benda wakaf yang dapat dimanfaatkan, dan kegiatan memanfaatkan harta benda wakaf tersebut dengan tetap menjaga agar harta benda wakaf tersebut tetap ada, kemudian hasil pemanfaatan dari wakaf tersebut diberikan kepada pihak yang berhak menerimanya dengan niat mendekatkan diri kepada Allah S.W.T.

\section{Perjalanan Wakaf di Indonesia dari Wakaf Tanah hingga Wakaf Uang}

Era Pra Kolonial, pada masa ini tidak ada peraturan perwakafan secara tertulis, seluruh peraturan perwakafan hanya diatur oleh hukum adat yang hidup di tengahtengah masyarakat.

Era Kolonial, pada masa ini perkembangan wakaf Indonesia dapat kita lihat salah satunya melalui beberapa surat berikut ini: Pertama, Surat Edaran sekretaris Governemen pertama tanggal 31 Januari 1905, No. 435, sebagaimana termuat di dalam Bijblad 1905 No. 6196, tentang Toezicht op den bouw van Muhammadaansche bedehuizen. Kedua, Surat Edaran dari sekretaris Governemen tanggal 4 Juni 1931 nomor 1361/A, yang dimuat dalam Bijblad 1931 nomor 125/A tentang Toezicht van regeerin op Muhammadaansche bedehuizen, vrijdagdiensten en wakafs. Ketiga, Surat Edaran sekretaris Governemen tanggal 24 Desember 1934 nomor 3088/A sebagaimana termuat di dalam Bijblad tahun 1934 No. 13390 tentang Toezicht van de regeering op Muhammedaansche bedehuizen, vrijdag diesten en wakafs. Keempat, Surat Edaran sekretaris Governemen tanggal $27 \mathrm{Mei}$ 1935 nomor 1273/A sebagaimana termuat dalam Bijblad 1935 nomor $13480 .^{6}$

\footnotetext{
${ }^{4}$ Al-Khotib, Syamsu al-din Muhammad bin Ahmad al-Sarbini, Mughni al-Muhtaj sarah Minhajul althalibin, Jilid 2 (t. Daar al Fikr.T.th.) hIm. 376

${ }^{5}$ Mansur bin Yunus Al-Buhuti. Sarah Muntaha al-Iradat, Jilid 2 (t. Daar al-fikr.T.th). hlm. 489

${ }^{6}$ Bank Indonesia, Wakaf: Pengaturan dan Tata Kelola yang Efektif, Seri Ekonomi dan Keuangan Syari'ah, Departemen Ekonomi dan Keuangan Syari'ah Bank Indonesia dan Departemen Ekonomi dan
} 
Berdasarkan keempat surat tersebut, dapat diketahui bahwa pada masa kolonial wakaf tetap ada dan para penjajah memberikan kesempatan kepada umat islam untuk memenuhi keperluan keagamaanya dengan memberikan kepada Bupati untuk memutus perkara jika terjadi sengketa tanah wakaf.

Era Orde Lama, Wakaf sudah memiliki dasar hukum yang lebih kuat karena wakaf telah mulai diatur dalam Undang-Undang, yaitu Undang-Undang Nomor 5 Tahun 1960 Tentang Pokok-Pokok Agraria, yaitu pada Pasal 5, 14 Ayat (1), 49 Ayat (2) dan (3).

Era Orde Baru, pada masa ini aturan pelaksanaan tentang wakaf dari UndangUndang Agraria yang telah ada sebelumnya mulai dibuat yaitu pada Peraturan Pemerintah (PP) Nomor 28 Tahun 1977 tentang Perwakafan Tanah Milik. Peraturan tersebut merupakan aturan pelaksanaan dari Pasal 49 ayat (3) dari UU No. 5 Tahun 1960 tentang Pokok Agraria.

Era Reformasi, pada masa ini wakaf telah memiliki Undang-Undang yang secara eksplisit mengatur tentang wakaf yaitu Undang-Undang Nomor 41 Tahun 2004 Tentang Wakaf dan peraturan pelaksananya yaitu Peraturan Pemerintah Nomor 42 Tahun 2004 Tentang Peraturan Pelaksana Undang-Undang Nomor 41 Tahun 2004 Tentang Wakaf. Pada era ini juga wakaf uang mulai diberlakukan melalui Fatwa Majelis Ulama Indonesia (MUI) tentang wakaf uang yang dikeluarkan pada 11 Mei 2002.

\section{Wakaf Uang dalam Pandangan Syari'ah}

Penulis belum menemukan dasar hukum syari'ah baik ayat al-quran maupun hadist yang menjelaskan bahwa di zaman Rosulullah S.A.W. pernah terjadi wakaf uang atau wakaf uang secara eksplisit pernah diperintahkan oleh Rosulullah S.A.W., yang pernah penulis temukan hanyalah wakaf tanahnya Abu Tholhah yang disebut bairuha, wakaf sahamnya Umar bin Khottob di Khaibar, Wakaf kuda, pedang dan zirah perangnya para Shohabah.

Hal ini karena wakaf uang dikategorikan sebagai sedekah yang dikelola oleh baitul mal. Maka, wakaf uang yang terjadi pada zaman sekarang menurut penulis murni merupakan ijtihad para ulama fiqih setelah zaman Rosulullah S.A.W., yang selama pengelolaanya dan pengembanganya tidak bertentangan dengan syari'ah, maka wakaf uang diperbolehkan atas dasar kaidah fiqih al-ashlu fil mu'amalat ibahah, segala sesuatu dalam mu'amalat dibolehkan selama tidak ada dalil yang melarangnya.

\section{Teori dan Asas Lahirnya Peraturan Wakaf Uang}

Selain teori ushul fiqih tentang mu'amalat, terdapat beberapa teori dan asas yang mendukung lahirnya peraturan dan/atau legalitas wakaf uang di Indonesia. salah satu teori tersebut adalah Teori hukum progresif.

Keuangan Syari'ah Fakultas Ekonomi dan Bisnis Universitas Airlangga, (Jakarta: Bank Indonesia, 2016), hal. 183-190 
Pada saat masyarakat sudah berkembang maju sampai pada titik peraturan sudah tidak dapat lagi menaungi perkembangan tersebut, maka pada saat itu lah terjadi kekosongan hukum dan untuk mengisi kekosongan hukum diperlukan pembaharuan hukum. pembaharuan hukum tersebutlah yang disebut sebagai hukum progresif. Peristiwa ini sejalan dengan wakaf, pada era pra kolonial, aturan wakaf hanya mengatur wakaf dalam bentuk tanah untuk kegiatan peribadatan, berbeda dengan zaman sekarang aturan perwakawafan sudah mengatur tentang wakaf uang untuk kegiatan investasi.

Hal ini terjadi karena pada era pra kolonial orang kaya adalah para raja dan bawahannya, pada era kolonial, orang kaya adalah orang yang dekat dengan para kolonial, berbeda dengan orang kaya pada era pasca kolonial yaitu orang yang memiliki tanah di mana-mana, kemudian berubah orang kaya berikutnya adalah orang yang memiliki kontrakan toko atau rumah atau kos-kosan di mana-mana, sampai pada akhirnya di zaman sekarang, orang kaya adalah orang yang memiliki saham di mana-mana. Maka wakaf hadir untuk menyesuaikan diri agar para pemilik saham mau mewakafkan sahamsaham mereka, saham dalam bentuk lembaran saham maupun saham dalam bentuk vang.

Adapun untuk asas hukumnya yaitu asas hukum perdata yang menjelaskan tentang kebebasan berkontrak, selama perjanjian dalam kontrak tidak bertentangan dengan peraturan perundang-undangan yaitu, maka perjanjian tersebut sah. Adapun syarat untuk melakukan sebuah perjanjian ada pada Pasal 1320 KUHPerdata diantaranya adalah kesepakatan saling mengikat, kedua belah pihak atau lebih harus memiliki kecakapan dalam melakukan suatu perbuatan hukum, adanya suatu hal tertentu dan suatu sebab yang diperkenankan.

\section{Riba dan Macam-macam Riba}

Riba secara bahasa memiliki arti sesuatu yang sengaja ditambahkan. Adapun pembagian riba berdasarkan macamnya dibagi mejadi dua, yaitu riba fadhl dan riba nasiah, adapun penjelasan keduanya adalah sebagai berikut:

Riba Fadhl

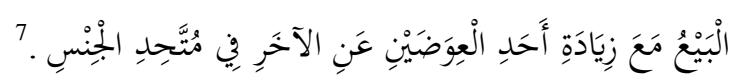

Riba fadhl adalah sesuatu yang sengaja ditambahkan pada saat pertukaran dua barang yang sama jenisnya, seperti menukarkan $1 \mathrm{Kg}$ beras dengan 1,5 $\mathrm{Kg}$ beras, maka selisih antara $1 \mathrm{Kg}$ beras dan 1,5 $\mathrm{Kg}$ beras yaitu 0,5 $\mathrm{Kg}$ beras tersebut lah yang disebut sebagai riba fadhl, begitu pula dengan seperti yang banyak terjadi pada saat kita

\footnotetext{
${ }^{7}$ Muhammad bin Abi Al-Abbas Ahmad bin Humajah bin Shihab al-din al-syafi'i, Nihayat al-Muhtaj Ila Sarah al-Manhaj Fi Madzhab, Madzhab al-Muallaf Syafi'i, Maud'u al-Murji'i Furu' al-Fiqh al-Syafi'i, Juz 3 (t. Mustafa Al-Haly.T.th.) hlm. 409
} 
menukarkan uang di beberapa oknum toko money changer, biasanya mereka menukarkan satu lembar uang Rp.100.000,- dengan Sembilan lembar vang Rp.10.000,- maka selisih antara Rp.100.000,- dan Rp.90.000,- yaitu Rp.10.000,- tersebut lah yang disebut sebagai riba fadhl.

Riba Nasiah

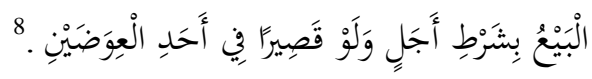

Riba nasiah adalah sejumlah uang yang sengaja ditambahkan pada saat seseorang yang meminjam uang melunasi hutangnya. Seperti seseorang yang meminjam uang Rp. 5.000,- namun uang yang dikembalikanya Rp.5.600,- maka selisih antara Rp.5.000,- dan Rp.5.600,- yaitu Rp.600,- merupakan riba nasiah. Riba jenis ini lah yang menurut penulis masih eksis dalam pelaksanaan pengelolaan dan pengembangan wakaf uang di Indonesia.

\section{Konsep Mudharabah}

Mudharabah atau bagi hasil merupakan salah satu skema atau pola kerjasama pemanfaatan harta benda wakaf yang tidak bertentangan dengan syari'ah. Konsep mudhorobah secara prakteknya dapat kita lihat dari praktek perdagangan yang pernah dilakukan antara Rosulullah dan Siti Khodijah.

Pada saat itu, Siti Khodijah memberikan Rosulullah barang dagangan dan memberikan persediaan makanan yang cukup yang dibutuhkan Rosulullah selama perjalanan dan berjualan barang dagangan milik Khodijah. Pada saat sepulangnya Rosulullah dari perjalanan perniagaanya tersebut, baru lah seluruh hasil perdagangan dan sisa barang dagangan tersebut dihitung, jika hasil penghitungan tersebut pemilik barang dagangan mendapatkan keuntungan, maka keuntungan tersebut dibagi sesuai dengan perjanjian antara pemilik barang dan penjual barang dagangan. Akan tetapi, apabila hasil penghitungan tersebut mengalami kerugian, maka penjual barang dagangan tersebut tidak menerima bayaran apapun dari pemilik barang dan tidak diwajibkan untuk membayar kerugian tersebut.

Sebagai contoh, apabila seseorang meminjam Rp.1.000,- maka jumlah yang harus dikembalikanya pun Rp.1.000,-. Jika orang yang meminjam mengembalikan Rp.1.500,maka selisih antara Rp.1.000,- dan Rp.1.500,- yaitu Rp.500,- merupakan riba. Dan jika orang yang meminjamkan mengembalikan Rp.500,- Maka orang yang meminjam telah mengambil hak orang yang dipinjaminya sebesar Rp.500,-. Mudhorobah sebagaimana yang telah dijelaskan oleh penulis sebelumnya merupakan mudhorobah yang terdiri atas pemilik modal dan pelaku usaha seperti halnya CV pada sebuah bidang usaha yang terdiri atas komoditer aktif dan komoditer pasif.

Sedangkan bentuk mudhorobah lainya yaitu mudhorobah yang seluruh penanam modalnya merupakan pelaku usaha, pada jenis mudhorobah ini, seluruh kerugian dan

\footnotetext{
${ }^{8}$ lbid.
} 
keuntunganya dibagi menjadi dua atau sesuai dengan yang disepakati. Sebagai contohnya pihak a dan b berencana melakukan bisnis jual beli aqua botol pada saat acara wisuda di kampus, pihak a memberikan Rp.100.000,- sebagai modal dan pihak b pun memberikan jumlah yang sama yaitu Rp.100.000,-. Kemudian kedua penanam modal tersebut sama-sama menjual aqua botol apabila mendapat keuntungan, maka seluruh keuntunganya dibagi menjadi dua begitu pula apabila keduanya mendapat kerugian, maka kerugianya dibagi menjadi dua.

Namun, apabila pihak a memberikan uang Rp.150.000,- sebagai modal dan pihak b hanya memberikan Rp.50.000,- sebagai modal, kemudian kedua penanam modal tersebut turut melakukan penjualan aqua botol tersebut, maka apabila mendapatkan keuntungan, maka pembagian keuntunganya adalah $75 \%$ dan 25\%, begitu pula apabila keduanya mendapatkan kerugian, maka pembagian kerugianya pun $75 \%$ dan $25 \%$. Keduanya dapat menentukan pembagian keuntungan dan kerugian dengan jumlah presentase lainya, dengan syarat keduanya sama-sama menerima atau sama-sama menyepakati hal kesepakatan tersebut.

Dengan demikian dapat disimpulkan bahwa bagi hasil artinya membagi apa yang telah dihasilkan, apabila hasilnya adalah untung, maka bagi hasil diartikan sebagai bagi keuntungan, namun apabila hasilnya adalah rugi, maka bagi hasil diartikan sebagai bagi keuntungan. Ini lah yang seharusnya diterapkan dalam konsep pelaksanaan wakaf uang di Indonesia. sayangnya konsep wakaf uang di Indonesia hari ini hanya menerapkan konsep bagi hasil keuntungan jika pengelolaan wakaf uang tersebut mendapatkan keuntungan. Adapun jika terjadi kerugian, maka seluruh kerugianya dilimpahkan kepada nazhir selaku pihak pengelola wakaf uang.

\section{Konsep Pinjam meminjam dengan riba dan tanpa riba}

Pada prinsip dasarnya, jumlah uang yang dipinjam dengan uang yang dikembalikan haruslah sama, jika terdapat perbedaan antara jumlah uang yang dipinjam dengan jumlah yang dibayarkan, maka apabila jumlah yang dibayarkan lebih besar dari jumlah pinjaman, selisih uang tersebut dalam islam disebut riba. Dan apabila jumlah uang yang dibayarkan lebih kecil dari jumlah pinjaman, selisih uang tersebut dalam islam disebut zholim, karena orang yang meminjam telah mengambil hak orang yang telah memberikanya pinjaman kepadanya.

\section{Konsep Pelaksanaan Wakaf Uang yang Tidak Berunsurkan Riba}

Wakaf uang berdasarkan waktunya dibagi menjadi dua, yaitu wakaf uang jangka waktu sementara dan wakaf untuk jangka waktu selamanya. Pertama, wakaf uang yang diwakafkan untuk jangka waktu sementara, dapat dikelola namun tidak dapat dikembangkan. Hal ini karena sifat wakaf uang untuk jangka waktu sementara bersifat titipan atau wadi'ah, landasan pemikiran ini karena wakaf uang untuk jangka waktu sementara 
akan diambil oleh wakif pada waktu yang telah dituangkan dalam akta ikrar wakaf dengan jumlah yang sama seperti saat wakif mewakafkan uang tersebut. Oleh karena itu, wakaf uang tersebut tidak boleh berkurang. Boleh dikembangkan, namun pengembangan tersebut tidak sebagai modal usaha, karena dalam dunia dunia perdagangan untung rugi hanya dapat diprediksi, tidak dapat dipastikan. Maka, sebaiknya uang tersebut hanya dipinjamkan, tidak disertakan sebagai modal dalam bentuk usaha apapun.

Yang kedua, yaitu wakaf uang untuk jangka waktu selamanya, wakaf uang untuk jangka waktu selamanya sebaiknya tidak diinvestasikan dalam bentuk lembaran saham karena lembaran saham nilai dan harganya naik turun tidak pasti, nazhir tidak dapat memastikan keuntungan, yang dapat nazhir lakukan hanya memprediksi keuntungan, maka untuk menghindari hilangnya wakaf uang tersebut, sebaiknya wakaf uang tidak dibelikan lembaran saham. Peruntukan wakaf uang yang tidak akan hilang, salah satunya dengan cara membeli tanah seperti lahan perkebunan, sawah, pemakaman umum, atau digunakan untuk membangun masjid, sekolah, rumah sakit, market, dan lain sebagainya yang menurut perhitungan nazhir memiliki prospek yang menguntungkan dengan kemungkinan resiko kerugian hampir mencapai o\%.

\section{Kesimpulan}

Disamping dasar hukum wakaf uang adalah ijtihadi, sehingga konsep pelaksanaan wakaf uangnya pun ijtihadi. Saat ini Indonesia belum memiliki bank syari'ah seperti halnya baitul mal, yang tidak mencari keuntungan dengan mencari-cari celah hukum sehingga menghalalkan banyak cara. Kedua hal ini lah yang membuat riba masih eksis dalam konsep pelaksanaan wakaf uang di Indonesia.

Upaya yang penulis tawarkan untuk dapat menghilangkan unsur riba adalah dengan membelanjakan wakaf uang untuk jangka waktu selamanya untuk membeli bidang tanah atau untuk membangun bangunan untuk kepentingan ibadah atau pendidikan atau kesehatan atau bidang lainya yang tidak bertentangan dengan ketentuan peraturan perundang-undangan dan prinsip syari'ah. Adapun untuk wakaf uang dalam jangka waktu tertentu atau sementara pengelolaanya dilakukan dengan pola pinjam meminjam, tidak dikembangkan melalui kegiatan penanaman modal dalam bentuk usaha apapun, karena wakaf uang tersebut tidak boleh berkurang jumlahnya dan akan diambil pada waktu yang telah ditetapkan wakif pada ikrar wakaf sedangkan dalam kegiatan penanaman modal keuntungan dan kerugian hanya dapat diprediksi atau tidak dapat dipastikan. 
Abdullah Ubaid, Analisis Hasil dan Metode Fundraising Wakaf Uang Badan Wakaf Indonesia (BWI), Jurnal Bimas Islam, Vol. 7, Tahun 2014, ISSN: 1978-9009, (Jakarta: 2014) http://simbi.kemenag.go.id/pustaka/images/materibuku/Buku\%20Jurnal\%20 7.4.pdf diakses pada tanggal 1 Agustus 2019

Al-Buhuti, Mansur bin Yunus. Sarah Muntaha al-Irâdat, t. Daar al-fikr.T.th.

Al-Khotib, Syamsu al-din Muhammad bin Ahmad al-Sarbini. Mughni al-Muhtaj sarah Minhajul al-thalibin. t. Daar al Fikr.T.th.

Amin bin Umar (Ibnu Abidin), Muhammad. Raddu Muhtar Ala Ad-darul Mukhtar, t. Ihya at-Turats.T.th.

Bank Indonesia, Wakaf: Pengaturan dan Tata Kelola yang Efektif, Seri Ekonomi dan Keuangan Syari'ah, Departemen Ekonomi dan Keuangan Syari'ah Bank Indonesia dan Departemen Ekonomi dan Keuangan Syari'ah Fakultas Ekonomi dan Bisnis Universitas Airlangga, Jakarta: Bank Indonesia. 2016.

Ilyas, Muhammad. Sarah Min al-jalil 'ala Mukhtasor Al-alâmat al kholil, t. Daar shadir. T.th.

Muhammad bin Abi Al-Abbas Ahmad bin Humajah bin Shihab al-din al-syafi'i, Nihayat alMuhtaj Ila Sarah al-Manhaj Fi Madzhab, Madzhab al-Muallaf Syafi'i, Maud'u alMurji'i Furu' al-Fiqh al-Syafi'i, t. Mustafa Al-Haly.T.th.

Peraturan Pemerintah Nomor 25 Tahun 2018 Tentang Peraturan Pelaksana UndangUndang Nomor 41 Tahun 2004 Tentang Wakaf.

Undang-Undang Nomor 41 Tahun 2004 Tentang Wakaf. 
244 | Asy-Syari'ah Vol. 21 No. 2, Desember 2019 


\begin{abstract}
Asy-Syari'ah (P-ISSN : 2086-9029 E-ISSN: 2654-5675) is a periodical scientific journal that publishes various results of studies and research, literature review, and other scientific works whose scope covers the field of Islamic law/sharia, law and society in monodisciplinary, interdisciplinary, and multidisciplinary manners. The journal aims to expand and create innovative concepts, theories, paradigms, perspectives and methodologies in the above said scope. The Journal is published twice a year (june and december) by Faculty of Shariah and Law, Sunan Gunung Djati State Islamic University Bandung in collaboration with Asosiasi Sarjana Syariah Indonesia (ASSYI).
\end{abstract}

\title{
EDITORIAL OFFICE:
}

Fakultas Syariah dan Hukum UIN Sunan Gunung Djati Bandung Jl. Raya A.H. Nasution No. 105 Cibiru Kota Bandung, 40614

Tlp/Fax: +022-7802278 Faks. 022-7802278

Website http://journal.uinsgd.ac.id/index.php/asy-syariah/index

E-mail: Jurnalasy-syariah@uinsgd.ac.id 